\title{
SOBRE EL SENTIDO DE LA VIDA: LA INFLUENCIA DE PAUL TILLICH EN LA PSICOTERAPIA EXISTENCIAL DE ROLLO MAY
}

\author{
ON THE MEANING OF LIFE: \\ THE INFLUENCE OF PAUL TILLICH ON ROLLO MAY'S EXISTENTIAL \\ PSYCHOTHERAPY
}

\author{
Lucía Carolina Fernández Jiménez* \\ IES La Torreta de Elche \\ Alicante-España \\ Recibido abril de 2020/Received April, 2020 \\ Aceptado septiembre de 2020/Accepted September, 2020
}

\begin{abstract}
RESUMEN
Desde que en el siglo XIX la psicología exigiera su reconocimiento como ciencia independiente, se ha ido separando progresivamente de la religión, llegando a caer en una perspectiva reduccionista que niega la dimensión espiritual del ser humano. Sin embargo, la Psicoterapia Existencial de Rollo May, profundamente influida por el teólogo existencialista Paul Tillich, es un ejemplo de cómo la práctica terapéutica no solo no está enfrentada a la religión, sino que incluso puede obtener de ella ciertas orientaciones de vital importancia para su quehacer.
\end{abstract}

Palabras Clave: Paul Tillich, Rollo May, Psicoterapia Existencial, Religión, Sentido de la Vida, Angustia.

\begin{abstract}
Since psychology demanded its recognition as an autonomous science in the 19th century, it has progressively gained independence from religion, to the extent of adopting a reductionist perspective that denies the spiritual dimension of the human being. Nevertheless, Rollo May's Existential Psychotherapy, deeply influenced by the existentialist theologian Paul Tillich, is an example of how the therapeutic practice not only is not opposed to religion, but also can obtain some orientations from it that are of vital importance for its task.
\end{abstract}

Key Words: Paul Tillich, Rollo May, Existential Psychotherapy, Religion, Meaning of Life, Anguish.

\section{INTRODUCCIÓN}

Cuando la psicoterapia existencial, paradigma psicológico profundamente arraigado en la filosofía, se pregunta por el sentido de la vida, lo hace atendiendo a una imagen determinada del ser humano. Ahí es cuando aparece el existencialismo, entendiendo por existencialismo, no una escuela homogénea y sistemática, sino una determinada forma de entender al ser humano que subraya ciertas características de este como son su libertad y finitud, y cuyo origen más próximo podríamos situar en el siglo XIX con el filósofo Sören Kierkegaard. La búsqueda de significado, del sentido de la vida, se torna esencial en esta concepción de la persona, y en este artículo intentaremos analizar si en la búsqueda de ese sentido tiene cabida la religión y 
qué papel puede o debe otorgarle el terapeuta frente a sus pacientes.

El filósofo y teólogo protestante Paul Tillich llegó a Estados Unidos, procedente de Alemania, en 1933, donde comenzó a impartir clases en el Seminario de Unión Teológica de Nueva York. Allí conoció a Rollo May, quien acabaría convirtiéndose en uno de los padres de la psicoterapia existencial. La relación entre ambos duró ya toda la vida de Tillich, y la práctica psicoterapéutica de May quedaría por siempre marcada por su influencia. El propio Rollo May dejó constancia de esta influencia en la obra Paulus. Tillich as Spiritual Teacher, en la que describe cómo se conocieron y lo que este conocimiento supuso para su formación y su vida en general. Allí May describe a Tillich como un ser con gran personalidad, y como un profesor creativo y atento que llenaba cada espacio de sus clases por su gran "presencia escénica"1 (May, 1988, p. 25).

Rollo May, que había llegado al Seminario, no con el objetivo de ser predicador, sino con el deseo de reflexionar acerca de las cuestiones fundamentales del ser humano en una época en la que las personas vivían aún sacudidos por los horrores de la Primera Guerra Mundial, afirma de Tillich: "Me di cuenta la primera vez que escuché una conferencia de Paul Tillich, de que ahí había un gran maestro, y lo he sabido en todo momento desde entonces" (May, 1988, p. 116. Traducción propia).

Pero será El coraje de existir, publicado por primera vez en 1952, la obra de Tillich que recoja las ideas fundamentales que marcaron de forma profunda la práctica psicológica de Rollo May, aunque ya en una obra anterior a esa publicación, The art of couseling (1939), May menciona repetidas veces a su maestro y manifiesta su acuerdo con él en los puntos que pretendemos desarrollar en este artículo: la conveniencia de que la psicoterapia esté en conexión con la teología para encontrar el verdadero sentido de la vida, las diferencias entre la angustia normal y la angustia patológica y la pertinencia de una adecuada teoría respecto de los valores como centro de la salud mental, idea que ya era profundamente compartida por otros dos contemporáneos de Rollo May, Erich Fromm y Viktor Frankl, para quienes la salud mental está en relación directa con una adecuada manera de entender al ser humano que tenga en cuenta la existencia de unos valores objetivos hacia los que la persona tiende.

\section{ASUMIR LAANGUSTIA EXISTENCIAL}

Para desarrollar estas ideas vamos a partir de uno de los axiomas principales en el pensamiento de ambos autores: no toda angustia presente en el ser humano es patológica, por lo que no toda angustia debe ser anulada. Con ello, no solo están señalando que existe un tipo de angustia connatural al ser humano, sino que esta no puede ser abandonada más que al precio de abandonarnos a nosotros mismos y no tomar conciencia de nuestra propia existencia. La vida auténtica solo lo puede ser en la medida en que adquiere conciencia de la angustia del vivir.

Esta angustia del vivir es denominada por Tillich angustia existencial y se manifiesta de tres modos posibles dependiendo de cuál sea su objeto:

\section{Angustia del sino y de la muerte}

Esta es la angustia más básica, universal e ineludible. Tillich la denomina angustia óntica y se refiere a la conciencia de la finitud temporal que acompaña al ser humano. Pero en esta conciencia de finitud también podemos diferenciar dos elementos de angustia: por un lado, la angustia de la muerte, que hace referencia a la conciencia de la "pérdida del yo que implica la extinción biológica" (Tillich, 1973, p.45), por otro, la angustia del sino, que se refiere a "la conciencia del ser finito de que es contingente en todo respecto, de no tener ninguna necesidad última" (Tillich, 1973, p. 47). La primera implica el saberse como ser mortal, la segunda hace referencia a ese descubrimiento de lo fortuito y accidental de la propia existencia.

\section{Angustia de la vaciedad y el absurdo}

Este tipo de angustia pertenece, según Tillich, al ámbito espiritual del ser humano, y hace referencia a la pérdida de un significado último, de un significado totalizador que dé sentido a todos los significados particulares que puedan aparecer en la vida de una persona. Surge de la pérdida de un centro espiritual que pueda dar respuesta al interrogante del significado de la existencia y es propio, señala Tillich, del ser humano contemporáneo, quien, en su intento de comprenderse y construirse como individuo, ha olvidado su dimensión espiritual y su pertenencia a un todo universal. Desde finales de la modernidad, "el derrumbamiento del absolutismo, el desarrollo del liberalismo y de la democracia y el nacimiento de la civilización técnica" (Tillich, 1973, p. 62) dan como resultado el predominio de la angustia de la vaciedad. 
Rollo May estará de acuerdo con Tillich en que este tipo de angustia es el propio de la persona de la sociedad contemporánea, ya que esta ha puesto en el centro de sus valores la creencia en la competencia individual como única forma de salvación y ha rechazado, por completo, la creencia de que la totalidad del proceso de la vida tenga un propósito. Esta creencia es, según May, la base de la actitud religiosa (en realidad, a lo que él llama religión es a esa actitud) y es la que el ser humano sano debe recuperar.

\section{Angustia de la culpa y la condenación}

Cuando hablamos de la angustia ante la culpa nos encontramos de lleno en el ámbito de la moral. Como existencialista, Tillich parte aquí del reconocimiento de que el ser humano es libertad, y de que, como tal, debe construirse por medio de sus decisiones. Pero toda decisión implica la conciencia de elección entre varias posibilidades que se presentan como probables y que van a terminar por definir aquello que yo soy. Surge, entonces, el sentimiento de culpa ante la elección por la probabilidad de errar en la misma, y este sentimiento despierta el juez que somos cada uno de nosotros de nosotros mismos.

Una vez realizada esta tipología de la angustia, Tillich las enmarca en lo que denomina "angustia existencial" y señala que, siendo esta intrínseca a la propia existencia, lo que debe hacer la persona es trabajar su aceptación para, de este modo, no caer en la desesperación y poder conquistar la autoafirmación y la valentía de vivir. Como ya señalamos antes, esta idea será crucial en la psicología existencial, para la cual la ansiedad existencial debe ser encarada con miras a una existencia plena y auténtica que reconozca nuestra fragilidad y finitud. Solo quien asume la amenaza continua de la muerte y el sinsentido puede vivir sin renunciar a su propia singularidad y construir su vida de manera consciente y responsable. Para la terapia existencial, un verdadero compromiso con la vida requiere un cierto grado de angustia existencial.

Sin embargo, no toda angustia es de este género, sino que también existe lo que tanto Tillich como May denominan angustia patológica y que hace referencia a la desesperación en la que cae aquel que no ha podido hacer frente a la angustia existencial.

En su obra El dilema del hombre May dedica todo un apartado a aclarar esta distinción entre angustia normal y patológica ${ }^{2}$. Allí dice estar de acuerdo con Kierkegaard al afirmar que "la libertad implica siempre una ansiedad potencial" (May, 2000, p. 76) y que "la ansiedad neurótica es el resultado de la reducción que ocurre porque la persona teme a la libertad" (May, 2000, p. 77), pero también manifiesta que la ansiedad se produce porque el ser humano ve amenazado "algún valor que el individuo considera esencial para su existencia como persona" (May, 2000, p.80). Estos valores pueden ser muchos y variados, pero cobran especial relevancia valores como el deseo de cuidado, de aprobación o el propio deseo de existir, que se ve amenazado continuamente por la idea de la muerte. Quizá sea la amenaza de la muerte la que más profundamente hace tambalear al ser humano, de ahí que May afirme estar de acuerdo con Tillich en su libro el Coraje de existir al sostener que "la ansiedad normal es sinónimo de la finitud humana" (May, 2000, p. 88).

De todo ello (el miedo a la libertad, la amenaza a los valores propios y el temor ante la muerte) se desprende que la angustia normal sea común al ser humano y por ello May niega que sea objetivo de la terapia liberar al individuo de esta angustia, sino que el objetivo es ayudarle a hacerle frente para crecer y vivir con más conciencia y plenitud. Pero cuando el sujeto es incapaz de hacer frente a la angustia normal y bloquea el desarrollo de su propia existencia, cuando oculta su responsabilidad ante la vida, cuando se siente incapaz de asumir su libertad, cuando no puede encarar la finitud y al mismo tiempo encontrar un sentido, entonces, aparece la ansiedad patológica. "La neurosis es la forma de evitar la nada evitando el ser" (Tillich, 1973. p. 67), que es lo mismo que decir que con el fin de evitar la muerte (angustia existencial) se termina evitando la vida (angustia patológica). Vivir plenamente significa reconocer las propias limitaciones como seres para-la-muerte, por utilizar la terminología heideggeriana, pero reconociendo, además, que es esta misma finitud la que nos recuerda que lo que hagamos con este tiempo del que disponemos es nuestra responsabilidad. En el fondo, la idea que aquí estamos manejando es la idea de la vida como proyecto personal, proyecto en el que continuamente hemos de estar decidiendo y construyéndonos con la dosis de angustia correspondiente que reporta tal ejercicio de libertad. Es este ejercicio vital consistente en vivir en primera persona, ejerciendo de autor de la misma y sin delegar nuestras decisiones a otros, el que provoca lo 
que acabamos de denominar la angustia existencial, pero solo será patológica cuando nos neguemos a aceptar que únicamente asumiendo este grado de angustia la vida será auténtica y real.

Por todo lo dicho se comprenderá que el modo de enfrentar la ansiedad sea aceptando la vulnerabilidad humana, la incertidumbre y la inevitabilidad de la libertad y de la muerte, pero también la sociedad tiene algo que hacer, según May a este respecto. ¿Por qué? porque una sociedad que ha perdido una base sólida de valores y ha caído en el relativismo (como afirma May refiriéndose a la sociedad americana de la segunda mitad del siglo $\mathrm{XX}$ ) no puede por menos que desorientar y confundir al individuo, que no sabrá qué elegir ante el "todo vale". Urge, por ello, enfrentarse al desafío de construir una sociedad con unos valores sólidos, en la que los individuos se relacionen entre ellos de forma significativa.

Creo que para hacer frente a este desafío y, por lo tanto, para superar el origen primordial de la ansiedad, se requiere la acción combinada no solo de los psicólogos y los psicopatólogos, sino también de los profesionales de todas las áreas de las ciencias sociales y también de la religión, la filosofía y el arte. He sostenido que en las épocas en las que los valores de una cultura gozan de unidad y fuerza, el ciudadano cuenta con los medios para enfrentarse y competir con la ansiedad. Cuando no hay unidad en los valores, el individuo, al sentirse sin amarras, tiende a evadir y reprimir su ansiedad normal. En consecuencia, monta la escena para su ansiedad neurótica en cierne (May, 2000. p. 79).

\section{DE LA POSIBLE RELACIÓN ENTRE PSICOLOGÍA Y RELIGIÓN}

Tomando en cuenta esta distinción entre angustia existencial y patológica podremos ahora analizar cuál sea la posible relación entre la psicoterapia y la religión. Partiendo de esta distinción, Tillich señala que la psicoterapia y la medicina han pretendido que toda angustia es patológica y que por ello mismo debe ser eliminada, como cualquier otra enfermedad. Con ello, se han hecho cómplices de una antropología errada. La concepción del ser humano que debe estar a la base de cualquier práctica terapéutica debe ser una concepción existencial que entienda que el propio vivir lleva emparejado un cierto grado de ansiedad.
Pero no ha sido así, la psicoterapia, en general, ha patologizado toda angustia y ha rechazado cualquier intento de entenderla o de incorporarla en su haber $^{3}$. Sin embargo, quienes sí la han incorporado, dice Tillich, han sido los sacerdotes, encargados desde siempre de aliviar la angustia del espíritu. Por ello, lo que el filósofo alemán va a proponer es una cooperación o alianza entre la teología y la psicoterapia al tratar la angustia:

El médico, especialmente el psicoterapeuta, puede implícitamente comunicar valor de ser y el poder asumir la angustia existencial sobre sí mismo. No se convierte en un ministro haciéndolo así, y nunca debe intentar reemplazar al ministro; pero puede ser una gran ayuda para la autoafirmación última, cumpliendo de esta forma una función ministerial. Y a la inversa, el ministro o cualquier otro puede ser una gran ayuda médica. No se convierte en médico, y ningún ministro debería aspirar a serlo como ministro, aunque puede irradiar poder de curación para la mente y el cuerpo y ayudar a eliminar la angustia neurótica [...]. La angustia patológica, una vez establecida, es objeto de curación médica. La angustia existencial es objeto de ayuda sacerdotal. Ni la función médica ni la sacerdotal están ligadas a sus representantes vocacionales: el ministro puede ser un médico y el psicoterapeuta un sacerdote, $\mathrm{y}$ todo ser humano puede ser ambas cosas en relación con el "prójimo". Pero las funciones no deben ser confundidas, y los representantes de una función no deben suplantar a los de la otra. La meta de ambos es ayudar a los hombres a alcanzar su plena autoafirmación, a conseguir el valor de ser (Tillich, 1973. p. 77).

Me he permitido citar este largo párrafo por la claridad que arroja acerca del tema que deseamos analizar. Fijémonos, en primer lugar, en que Tillich delimita las funciones de la medicina y de la teología, pero no así quién sea la figura que lleve a cabo dicha función, ya que la función puede ejercerla quien tenga valía para ella. Esta idea de poner el énfasis en las características personales del "sanador" más que en la técnica utilizada, también es una característica propia de la terapia existencial, para la que es muy importante que quien acompaña al doliente en su proceso de sanación y autoafirmación sea una persona con ciertas características muy humanas y empáticas y que "esté preparado para asomarse en los dilemas existenciales más 
profundos" (Martínez Robles, 2012, p. 409). La mayoría de los terapeutas de vertiente humanista han señalado que las características que ha de tener quien quiera dedicarse a la psicoterapia deben ser, entre otras, la capacidad de cuidar, proteger, acompañar y escuchar pacientemente al doliente, pero siempre desde el respeto a su libertad, ya que es él, y solo él, quien debe descubrir su propio camino. Por eso, el terapeuta debe siempre permanecer en un segundo plano y, aunque a veces proponga estrategias para aliviar síntomas incapacitantes, debe dedicarse, sobre todo, a acompañar al paciente "a hacerse cargo de su mundo, de sí, a cambiar formas de pensar, sentir y actuar y a que se responsabilice de sí y de su proceso de personalización" (Domínguez, 2011, p. 185).

En segundo lugar, como acabamos de señalar, Tillich delimita las funciones del ámbito de la religión y la psicología y nos recuerda que, una vez que la angustia se ha tornado patológica, se requiere la intervención de un médico que sea capaz de ayudar al individuo a escapar del corsé limitante que supone su estrecha forma de enfrentarse al mundo (sirvan como ejemplo patologías como la depresión, las fobias o la anorexia), pero que mientras nos mantengamos en el ámbito de la angustia existencial es función de la religión el despertar en el doliente el adecuado enfrentamiento con la propia existencia para su sanación.

Ahora bien, la parte final de la cita señala, en tercer lugar, que el objetivo último tanto de la religión como de la psicoterapia debe ser el de ayudar a las personas a alcanzar su plena autoafirmación. Aquí la postura de Tillich entronca de lleno con la postura que mantendrá Rollo May a lo largo de su obra. La función de la psicoterapia no es, como algunos han creído, borrar la angustia de la existencia, sino convertirla en motor de búsqueda y crecimiento. En los siguientes párrafos nos proponemos analizar esta idea.

Esa autoafirmación de la que habla Paul Tillich es la que también denomina "coraje de ser uno mismo", al que hace referencia el título de su ensayo. Allí sostiene que el existencialismo, como antropología filosófica, ha sido la máxima expresión del valor de ser uno mismo y que por ello debe ser asimilado como marco antropológico desde el que comprender la naturaleza humana. Ahora bien, el existencialismo ha entendido y explicitado ese valor se ser uno mismo, pero se ha olvidado del valor de ser como parte, afirma Tillich, y por ello hay que dar un paso más allá para encontrar una postura que integre la unicidad irrepetible que es el individuo y su pertenencia a un todo que lo abraza y lo sustenta. Solo así podrá alcanzar su plena autoafirmación y el sentido de la existencia. Esta integración y superación del polo personal y la participación en el todo se da, según el teólogo existencial, en la religión.

A diferencia de su maestro, Rollo May no está de acuerdo con que el enfrentamiento con la angustia existencial sea función de la religión, sino que la superación de la visión pragmática y cientificista de la práctica psicoterapéutica da cabida a que esta se ocupe también de cuestiones existenciales y espirituales que antes eran objeto solo de la religión. Mucho más cerca de entender la psicología como el estudio del alma que como ciencia que estudia la mente y la conducta de los individuos, cuyos grandes objetivos son describir, explicar, predecir y modificar la conducta, Rollo May entiende que en el ser humano hay una dimensión espiritual que la psicología debe atender si quiere comprenderlo y justamente es en este sentido en el que la religión puede aportar algo a la función terapéutica del psicólogo.

En última instancia, la relación entre la religión y la psicoterapia estará siempre relacionada con una cuestión ya apuntada, pero aún no explicitada: la cuestión del sentido de la vida. Ya en su primera obra, May sostiene que cuanto más se acerca el ser humano al ámbito de la terapia más se acerca al enfrentamiento con temas puramente teológicos y esto es así porque una de las preocupaciones básicas de la persona es la del sentido de la vida, preocupación que va unida, evidentemente, a la conciencia de la muerte y a la soledad radical ${ }^{4}$. Cuál sea el sentido de la vida es una preocupación para la práctica psicoterapéutica, y por supuesto, la religión se posiciona ante esta pregunta. Es más, May denomina actitud religiosa a una actitud básica de la persona frente a su existencia que acepta que "la totalidad del proceso de la vida tiene un propósito" (May, 1967, p. 217). Asimismo, afirma que la salud de la personalidad, que integra las dimensiones mentales y espirituales del individuo, requiere de un propósito de la totalidad de la vida además del propósito de $s u$ vida, ya que "uno no puede vivir en una isla de sentido rodeado de un océano de sinsentido" (May, 1967, p. 216).

Este propósito de la totalidad es lo que Irvin Yalom, otro de los principales representantes de la psicoterapia existencial norteamericana y discípulo 
de May, denomina significado cósmico, entendido como la aceptación de que "existe un diseño previo, externo y superior al individuo" (Yalom, 1984, p. 506). Pero Yalom, a diferencia de su maestro, se encuentra en la línea atea de la Terapia existencial $y$ entiende que el paciente no necesita encontrar ese significado cósmico para tener una vida mental saludable, aunque sí necesita encontrar un sentido a la vida para ello. Es decir, que Yalom estaría negando la afirmación anteriormente citada de May de que no es posible vivir con sentido rodeado de un sinsentido general, y se estaría situando del lado de algunas filosofías de la existencia que entienden que no hay significado en la totalidad, sino que lo único que es esencial al individuo es construir (no encontrar) su propio significado. Inventar un significado que sea capaz de otorgar una razón vital. Ahora bien, al mismo tiempo que habla de inventar, Yalom señala que no cualquier actividad es capaz por sí misma de proporcionar esa razón buscada, lo que nos pone sobre el aviso de que no es válida cualquier forma de fabricar sentidos, sino que existen ciertas actividades válidas objetivamente y que su realización es capaz de conceder el propósito que otorga plenitud a la vida. Estas actividades "son buenas, son correctas, son satisfactorias intrínsecamente hablando y no necesitan justificarse en ninguna otra motivación" (Yalom, 1984, p. 515).

En su principal obra, Psicoterapia Existencial, Yalom señala que entre estas actividades se encuentran:

1. El altruismo. Que consiste en "servir a otros y participar en obras de caridad" (Yalom, 1984, p. 515) con el objetivo de hacer del mundo un lugar más habitable, justo y humano.

2. La consagración a una causa. Es decir, trabajar por el cumplimiento de una causa que merezca la pena, ya sea esta la familia, el Estado o la ciencia, por citar algunas.

3. La creatividad. Señala Yalom que "el hecho de crear algo nuevo, original, bello o armonioso, constituye un poderoso antídoto contra la falta de sentido vital" (Yalom, 1984, p. 519), de donde se deduce que la creación es un fin en sí mismo que no necesita justificación ni está sujeta a otros fines.

4. La solución hedonista. Entendiendo por ella el mero disfrute de los placeres sencillos de la vida, la capacidad de dejarse sorprender por el milagro de la existencia y la capacidad de valorarla en aquello que nos ofrece. Sería algo así como un vivir la vida estando abierto a la captación de aquello que se nos ofrece y ser capaz de disfrutarlo.

5. La autorrealización. Este término, clave en las escuelas psicológicas de carácter humanista, hace referencia a la creencia de que el significado de la vida proviene de la capacidad del individuo para desarrollar sus potencialidades, características intrínsecas que esconden nuestros talentos singulares como individuos. En último término, lo que la autorrealización esconde es la capacidad de convertirse en aquello que se es capaz de ser.

6. La trascendencia de uno mismo. La última de las actividades que Yalom señala como capaces de generar el sentido de la vida es lo que podríamos denominar la capacidad de olvidarnos de nosotros mismos para volcarnos en los otros o en el mundo. Esta capacidad implica de lleno nuestra habilidad y talento para amar. Cuando uno ama se olvida de sí mismo y se implica de lleno en el cuidado del objeto amado, que supera los límites personales y egocéntricos. Así, esta trascendencia puede entenderse, por ejemplo, como el deseo de cuidar de los hijos, como la aceptación del ciclo vital, pero también como la creencia en Dios. De este modo volvemos a cerrar el círculo del sentido cósmico al que antes hacíamos referencia.

Rollo May, a diferencia de la posición de su discípulo, y en la misma senda que el creador de la logoterapia Viktor Frankl, interpreta el sentido de la vida desde lo que él entiende como una perspectiva puramente religiosa, al suponer que dicho sentido proviene de la aceptación de un sentido último y totalizador que nos saca de nuestra egocentricidad y nos permite asumir nuestra participación en el logos divino del significado ${ }^{5}$. Es Tillich quien explicita aún más cuál sea el modo de la experiencia religiosa que integra de manera perfecta esa unión del ser como parte de un todo y ser como sí mismo (como singularidad). Para ello distingue entre la experiencia de carácter místico (poniendo como ejemplo la filosofía de Spinoza), la experiencia del encuentro personal con Dios (recordemos, por ejemplo, la experiencia pascaliana descrita en el Memorial) y la experiencia de la fe, afirmando que solo en esta última se da una verdadera trascendencia y aceptación de ambos polos. 
Si retomamos las palabras de Tillich y las comprendemos a la luz de las de May, la fe aporta a la persona el sentido de la totalidad del universo al que ella pertenece como parte. Pero hemos de señalar también que para Tillich es importante comprender la fe dentro del marco de la religión protestante a la que él pertenece. El protestantismo, a diferencia del catolicismo que sitúa en el centro la acción, pone el énfasis en la fe en el perdón divino. Y es esta idea la que lleva a Tillich a sostener que la fe es la verdadera autoafirmación, ya que mediante la fe el individuo se acepta a sí mismo al sentirse aceptado: "El valor de ser es el valor de aceptarse como aceptado a pesar de ser inaceptable" (Tillich, 1973, p.157).

Así, la inaceptabilidad del ser humano que se revelaba en la angustia existencial y que le recordaba su finitud, su contingencia, su posibilidad de error o su eterna búsqueda de sentido vital, es reconducida en la fe, la que hace posible que, en vez de caer en la desesperación, se acepte como ser frágil y permita ser ayudado y acogido en un todo de significación mayor.

A pesar de la nada que asoma continuamente en el ser humano a pesar de experimentarse este como ser carente, puede y debe tener el valor de autoafirmarse y la experiencia de ese valor es llamada fe por Tillich, un estado que es capaz de otorgar significado en cualquiera de las modalidades de la angustia existencial a las que antes hemos hecho referencia: en la muerte, en la culpa e incluso en el absurdo, ya que el estado de aceptar el absurdo ya es en sí mismo un acto significativo.

Pero no toda religión puede ser entendida en este sentido significativo, es decir, que no toda manera de experimentar la religión otorga el sentido a la vida que estamos buscando. Rollo May dedica gran parte de su primera obra a distinguir entre la religión que fomenta el coraje de existir y la religión neurótica. Esta última es la que fue descrita por Freud quien la entendió como fuente de neurosis colectiva. Pero esa religión que pretende eliminar toda angustia y que surge de la cobardía ante el verdadero enfrentamiento con la existencia, no es más que una forma de huida, una estrategia para escapar de la soledad y la ansiedad. Entender así la religión es entenderla como huida de la vida y sumerge a la persona en un perpetuo estado de infantilismo que quiere apartarla de la inseguridad y la impredicibilidad intrínseca a la propia existencia.
Para ejemplificar esta forma errónea de entender la religión, May nos propone el ejemplo de Harold K. ${ }^{6}$, un cura protestante aquejado de crisis nerviosas. May, que se convirtió en su psicoterapeuta, nos dice de él que se trataba de un hombre obsesionado por mantener el respeto de la gente de su parroquia y que, en su intento de escapar del sentimiento de culpa y fragilidad humana, convirtió su vida en un experimento de control. Quería controlarlo todo para hacerse merecedor de la seguridad y su técnica consistió en controlar todos los pequeños placeres o tentaciones de la vida: no tomaba café, no fumaba, no tomaba chocolate, no bailaba... Se dedicaba a ponerse límites y demostrar que podía controlarse. Pero estas exigencias, dice May, lejos de situarle al lado del resto de los hombres, le otorgaban una extraña sensación de superioridad que le separaba de los otros, como si hubiese traspasado una línea que le permitía estar al otro lado de la barrera, al lado de los salvados. "Su alegría surgía del triunfo sobre los otros" (May, 1967, p. 211), pero así su vida era lo contrario de una vida abundante, que solo puede conseguirse fomentando el vínculo con las personas. Su religión no le ofrecía alegría de vivir, que debe ser el objetivo de la religión bien entendida, sino una sensación de tristeza y miedo solo disminuida con el control obsesivo sobre los pequeños placeres. Harold K. representa un mal uso de la religión.

Pero ese mal uso, como forma de compensar la inseguridad básica de la existencia, no solo puede ser practicado en el ámbito de la religión. May nos invita a reflexionar acerca de ello y nos propone el ejemplo de la ciencia. El ser humano, dice el psicoterapeuta americano, se ha agarrado a la ciencia como tabla de salvación del caos y la incertidumbre existencial, como manera de poner orden y dominar a la vida, buscando siempre poder predecir y controlar: "El individuo temeroso y superado por la impredecibilidad de la vida a menudo huye al laboratorio científico y allí alcanza un cierto dominio sobre las fuerzas de la vida y se siente protegido" (May, 1967, p. 212). Con la ciencia el ser humano siente la seguridad de lo que está controlado y responde a leyes regulares. Esta seguridad que comenzó a sentir plenamente el hombre moderno y que se ejemplifica en la máxima positivista "conocer para prever", llegará a su culmen en nuestros días en movimientos como el transhumanismo, para el que, la ciencia y la tecnología no solamente 
nos ayudarán a paliar el sufrimiento, sino que nos darán el suficiente dominio sobre la vida como para acabar con las limitaciones biológicas y vencer al envejecimiento y la muerte ${ }^{7}$.

Quede claro, pues, que este mal uso de la religión es un abuso de la misma, pero el verdadero sentido religioso nada tiene que ver con esto, sino que es una afirmación de la vida. La religión dice sí a la vida, afirma Rollo May, y con ello se sitúa en las antípodas de la interpretación nietzscheana de la misma, esa interpretación que tacha a la religión de castrante y manipuladora por intentar coartar todos los placeres de la existencia.

Sin embargo, para May, no toda religión puede ser así entendida. Hay una religión que debilita a la persona, pero hay otra que la fortalece y esa sí es fuente de salud mental. La religión que sostiene que hay una inteligencia, un propósito y una ley moral en el universo es dadora de sentido, pero este sentido solo puede surgir de un primer enfrentamiento con la finitud y la soledad. La verdadera creencia religiosa, la creencia en un Dios dador de sentido solo puede aparecer cuando "se es capaz de no pedir que le cuiden a uno, cuando se tiene el coraje de permanecer solo" (May, 1967, p. 162). Y esto es así porque la verdadera religión es amor y el amor solo puede darse en su plenitud cuando es independiente de lo que uno vaya a obtener a cambio. Así, si nos lanzamos a la religión solo como forma de obtener el cuidado y la protección que nos falta, el sentido amoroso de la experiencia religiosa se torna utilitarista y deja de ser ella misma. Pero cuando uno llega a la religión libre de intereses y capaz de confiar en sí mismo, en los otros y en el universo, la religión adquiere su poder curativo. Aparece la verdadera fe.

Esta es la fe de la que nos habla Tillich, esa fe en la que la persona se encuentra siendo aceptada y arropada dentro de un todo significador que le permite admitir sus limitaciones y le capacita para sobrellevar la angustia existencial e insertarla dentro de su propio ser. La fe le permite al ser humano obtener el coraje necesario para abrazar su propia vida y responsabilizarse de ella. Solo quien asume la ansiedad de vivir tiene la capacidad de crecer, porque la angustia existencial aparece cuando la persona se está haciendo cargo del dilema de la existencia. Así llama Rollo May a la naturaleza trágica que entraña en sí la existencia humana, una naturaleza dual que incluye en sí "polaridades y paradojas ineludiblemente humanas" (May, 2000, p. 9). Entre estas polaridades May pone especial énfasis en la polaridad entre el destino (el componente de necesidad que hay en la vida de cualquier individuo) y la libertad (el componente de elección irrenunciable que acompaña a toda existencia), pero también podríamos entenderlo en otros dilemas: el representado por Pascal como diferencia entre espíritu de geometría y de fineza, el nietzscheano entre el elemento apolíneo y el dionisiaco de toda existencia o el unamuniano entre razón y corazón, por poner algunos ejemplos.

Esta es otra de las ideas centrales de la obra de Rollo May y de toda psicoterapia existencial: reconocer la complejidad y las polaridades del ser humano. Solo comprendiendo el dilema humano y sus tensiones podremos comprenderlo sin simplificarlo, solo comprendiendo esa esencia trágica podremos ayudarlo, y el terapeuta tiene que tener en cuenta esto para no reducirlo a otro objeto de estudio más y para no caer en la tentación de intentar analizarlo antes que comprenderlo:

Ninguno de nosotros sabe si alguna vez podremos hacer de la disciplina psicológica una "ciencia de los seres humanos". Pero si enfrentamos el dilema del hombre, al menos estaremos ocupándonos de seres humanos y no de criaturas truncadas y absurdas reducidas a partes aisladas y sin centro alguno, partes que podemos poner a prueba ya que se ajustan a nuestras máquinas. Claro que esto, supone renunciar a nuestra propia necesidad, de poder y poner en claro nuestra necesidad de control. Solo entonces podremos albergar alguna esperanza de que nuestra obra perdure (May, 2000, p. 14).

En su intento de convertirse y adquirir el estatus de ciencia, objetivo que desde la modernidad ha alcanzado cualquier esfera de la vida, la psicología se ha ido separando progresivamente de la religión y ha eliminado cualquier carácter espiritual del ser humano ${ }^{8}$, al tiempo que lo ha ido convirtiendo en una máquina a la que poder arreglar cuando aparece el más mínimo reflejo de ansiedad o angustia, síntomas claros de que algo no va bien. Pero, como venimos diciendo, la angustia no es un síntoma de que algo no va bien, sino que es un reflejo de la propia naturaleza humana: contradictoria y laberíntica. Solo quien comprenda y acepte la angustia de la existencia estará tratando con el verdadero ser humano. 
Para la psicología existencial el ser humano no puede ser reducido a objeto de estudio, del mismo modo que no puede ser eliminada su angustia sino a riesgo de anular su humanidad. Porque vivir es arriesgarse, y arriesgarse produce ansiedad, pero no hacerlo significa perderse a sí mismo, dice May citando a Kierkegaard. La ansiedad viene provocada por la misma búsqueda de significación y por las distintas crisis de crecimiento por las que la persona pasa a lo largo de su vida, crisis en las que los valores, las creencias o las seguridades que nos sostenían en un momento deben ser cambiadas o superadas por otras. Estas crisis de crecimiento, por seguir con la terminología de May, pueden ser muy variadas según las circunstancias vividas por cada individuo, pero también hay algunos momentos vitales que suponen un cambio significativo en cualquier individuo y que requieren una recolocación de nuestros valores y una búsqueda interior, como podrían ser tomar la decisión de nuestra vocación, la decisión de tener un hijo o el enfrentamiento con la enfermedad propia o ajena. En cualquiera de estos momentos se produce en el individuo una ampliación de la conciencia y se requiere del valor de indagar en el propio ser. Pero ello va unido a una sensación de ansiedad que surge por el miedo a crecer, a construirnos, a tomar decisiones o a enfrentarnos con la finitud, por enfrentarnos, al fin y al cabo, con nuestra humanidad. Por ello el ser humano ha intentado, a lo largo de los años, escapar de esa ansiedad de mil y una formas: desde el divertimento del que habla Pascal (1983) en sus Pensamientos, hasta la caída en el "se" que nos describe Heidegger en Ser y Tiempo (1993), por citar algunas.

Se comprende, pues, por qué algunos han entendido que la religión no es más que otra forma de fuga y distracción, pero lo que aquí venimos sosteniendo es que esa forma de entenderla es una forma neurótica y falaz. Porque la verdadera fe no es pragmática, sino que nos libera del ansia de alcanzar la salvación justo porque nos libera de nuestra egocentricidad. El individuo religioso, dice May, deja de pensar en sí mismo de forma obsesiva y por ello mismo se hace cargo de la responsabilidad que tiene de vivir de forma adecuada en el todo del que forma parte. Esa forma adecuada de vivir supone la aceptación de unos valores objetivos y totalizadores, aceptación que asienta las bases de una vida sana ${ }^{9}$ :
La libertad, la responsabilidad, el coraje, el amor y la integridad interior son cualidades ideales que nunca nadie realizó a la perfección, pero que constituyen objetivos psicológicos que le dan sentido a nuestro movimiento hacia la integración (May, 1985a, p. 219).

Solo aquel para quien sus valores sean más fuertes que las amenazas a la vida (la contingencia, la enfermedad, el error, la conciencia de la muerte, etc.), podrá hacer frente a la ansiedad normal.

\section{EL EFECTO TERAPÉUTICO DE LA ACTITUD RELIGIOSA}

La religión, como es entendida en la obra de Rollo May, nada tiene que ver con lo que el psicólogo William James entiende como religión institucional ${ }^{10}$, sino con lo que él denomina religión personal, que hace referencia a la experiencia humana que incluye "los sentimientos, los actos y las experiencias de los hombres particulares en soledad, en la medida en que se ejercitan en mantener una relación con lo que denominan divinidad" (James, 1999, p. 34).

Lo que venimos sosteniendo es que May apoya la idea de que esta religión personal o actitud religiosa es valiosa como sistema terapéutico, y que lo es por las razones que se desarrollan a continuación:

1. Porque es vivida como creencia que encuentra un sentido y un propósito al universo, $\mathrm{y}$ encontrar un sentido es de suyo terapéutico. Esta creencia proporciona al ser humano la capacidad de confiar más allá de sus debilidades y limitaciones, curándolo del miedo a vivir. May señala que el neurótico siente el mundo como enemigo y que si fuese capaz de confiar en un sentido último podría escapar del miedo que le paraliza y encontrar el coraje que necesita para vivir.

En esta misma línea, Viktor Frankl, el padre de la logoterapia y el gran teórico del sentido de la vida, afirma que este sentido existe siempre, aunque el ser humano no lo encuentre y que por ello la práctica terapéutica tiene como objetivo último ayudar a la persona a encontrar (no a inventar) el sentido de la vida, un sentido que puede revestirse de diferentes formas a lo largo de la vida de un individuo, pero que nunca deja de existir. "Ningún psiquiatra, ningún 
psicoterapeuta -incluidos los logoterapeutaspueden decir a un enfermo cuál es el sentido, pero sí puede decirle muy bien que la vida tiene un sentido, y más aún: que lo conserva bajo todas las condiciones y circunstancias, gracias a la posibilidad de descubrir un sentido también en el sufrimiento" (Frankl, 2003, p. 33).

2. Porque toda actitud religiosa se relaciona profundamente con el amor, el cuidado y el compromiso. No hay vivencia y actitud religiosa si no es desde el amor. Es el amor el pilar fundamental de las distintas religiones, lo mismo que lo es de la salud y el bienestar mental. La experiencia amorosa se convierte en la obra de Rollo May, al igual que en la obra de otros psicólogos humanistas, en el núcleo necesario de toda auténtica curación, ya que mediante el amor la persona se afirma y afirma al otro, acepta (al otro o al universo) y se siente aceptado, cuida y se siente merecedor de cuidado. Quien ama y se ama tiene cuidado de los otros y de sí mismo, y así, vive su vida con la responsabilidad y el esmero de lo que merece la pena. Sin embargo, un fracaso en la dimensión comunitaria y amorosa es una patologización de la propia vida.

Tal es la importancia que otorga May al amor como fuente de sanación, que dedica gran parte de una de sus obras a señalar cómo el ser humano, a finales del siglo XX, está perdiendo la capacidad de amar y con ello se encuentra perdido en un caos de sinsentido que le lleva a acudir en masa a todo tipo de terapias. Junto con su capacidad de amar está perdiéndose a sí mismo. La obra en cuestión es Amor y voluntad en psicoterapia y en ella señala la deshumanización del ser humano contemporáneo, al mismo tiempo que la necesidad del amor como motor vital que arranque a la persona de la apatía en la que está inmersa.

3. Porque abre la subjetividad a la trascendencia. Para Rollo May la verdadera actitud religiosa posibilita escapar de la egocentricidad que aísla al ser humano de los otros y lo arrastra al aislamiento. Aceptar la trascendencia confiando en un sentido último y en comunión con los otros pasa por coger las riendas de la propia vida y asumir la libertad y la responsabilidad del vivir. En este sentido, la eternidad pasa a ser entendida como "una manera de relacionarse con la vida y no como una sucesión de mañanas" (May, 1985a, p. 214), manera que consiste en enfrentar la vida con coraje y de forma constructiva, en aceptar la finitud, en comprometerse con los otros y con el mundo del que formamos parte.

4. Porque la actitud religiosa tiene la convicción de que existen valores objetivos en la existencia humana por los que merece la pena vivir y morir. Mientras que la carencia de valores en las que se sumerge la persona la lleva a naufragar en el nihilismo y en la apatía, la creencia en unos valores dadores de sentido reporta al ser humano el impulso necesario para construir un mundo que merezca la pena ser habitado. La religión así entendida es una especie de "madurez emocional y ética" (May, 1985a, p. 201) que acepta un orden de valores que lo trascienden y que se adecua a vivir según ellos. Lejos del relativismo moral, la actitud religiosa propugna un objetivismo axiológico $y$ entiende que el sujeto debe reconocer estos valores para vivir una vida digna, porque "no todo vale en el camino de ser personas: el consumo de drogas es destructivo y la fidelidad al amigo es constructiva; la mentira es degradante y el respeto mutuo resulta personalizante; la codicia daña a la persona y la generosidad le libera y engrandece; la ira empobrece y el perdón plenifica" (Domínguez, 2011, p. 77). En este sentido, la psicología de Rollo May también es una invitación al reconocimiento de estos valores. El encuentro con ellos aportará al individuo el bienestar mental y espiritual propio del sujeto "sano".

\section{CONCLUSIÓN}

Como hemos visto, la primera obra que Rollo May publica, The art of couseling, está repleta de referencias explícitas a Dios y a la religión, sin embargo, esto no es así en el resto de su obra. A partir de esa primera publicación las referencias religiosas siguen teniendo mucha fuerza, pero de un modo más difuso e intimista, quizá más en la forma de experiencia del sentido último de la vida y de una forma determinada de vivir que exige compromiso y apertura a la humanidad.

De lo que no cabe duda es de que toda su obra se encuentra llena de innumerables referencias a personalidades importantes dentro del ámbito de la filosofía cristiana: San Agustín, Blaise Pascal, Sören Kierkegaard, Paul Tillich o Gabriel Marcel, 
por citar solo algunos. Todos ellos son autores de filosofía desgarrada que tienen en cuenta la naturaleza paradójica del ser humano, su pequeñez y su grandeza, su inmanencia y su capacidad de trascendencia, su finitud y su pertenencia a una divinidad mayor que lo abarca, y tienen en cuenta, también, que de esta naturaleza desgarrada y trágica de la persona parte su angustia existencial, que es la que nos recuerda que estamos enfrentando la vida adecuadamente y no que estamos anestesiados. La angustia existencial es un síntoma de una vida vivida cara a cara. "Eliminando lo incómodo, lo doloroso, lo cansado, la culpabilidad, la pena, lo que se ha eliminado es la vida personal, la alegría. Se ha perdido la pista del camino de la plenitud" (Domínguez, 2011, p. 89).

Asimismo, cuando Rollo May asume una perspectiva religiosa en el sentido amplio en el que lo venimos haciendo, lo hace también como crítica a la perspectiva chata y reduccionista de la psicología positivista. La concepción psicológica de May es una concepción profundamente crítica con lo que él mismo denomina la obsesión cientificista, obsesión que, en el marco de la psicología incurre en el error de caer en un reduccionismo humano que convierte al paciente en un ser unidimensional. Este reduccionismo físico se ha olvidado de los fenómenos espirituales que comporta la humanidad, por lo que urge volver a una antropología que contemple dichos fenómenos. Debido a que el objeto de estudio de la psicología "es la persona, un ser limítrofe, esto es, corporal, psíquico y espiritual, no basta su abordaje desde la mera ciencia empírica. Los métodos de las ciencias empíricas solo comprenden lo cuantitativo de la persona, pero no lo cualitativo" (Domínguez, 2011, p. 35). Si conseguimos devolver su dignidad a la dimensión espiritual del paciente, no entenderemos que la función del psicólogo sea la de curar al organismo estropeado, sino la de comprender sus dudas, miedos y dificultades vitales y ayudarlo a enfrentarlos en aras de una existencia plena. Tampoco será función de la psicoterapia ayudar al individuo a adaptarse o a alcanzar la felicidad, sino ayudarlo a escapar de los "modos inadecuados de vivir como persona" (Domínguez, 2011, p. 271), que son los que proporcionan "falsos caminos de crecimiento y maduración" (Domínguez, 2011, p. 271). A todo ello puede contribuir una actitud religiosa adecuada, proporcionando los valores y el sentido necesario para vivir.
Rollo May, quien se considera a sí mismo un fiel creyente, no cree, sin embargo, que la verdadera religión deba demostrar la existencia de Dios, sino que, al contrario, afirma estar de acuerdo con el que fue su maestro al afirmar: "Paul Tillich destaca que argumentar a favor de la existencia de Dios implica tanto ateísmo como esgrimir argumentos en contra de ella" (May, 1985a, p. 168). La actitud religiosa no se muestra en ocuparse de demostrar la existencia de Dios ${ }^{11}$, sino en la orientación total de la propia vida, una orientación basada en el sentido, el amor y el compromiso con uno mismo y con los demás.

Una de las mayores representantes en la actualidad de la psicoterapia existencial, Emmy van Deurzen-Smith (1993), podría estar de acuerdo con Rollo May en rescatar el papel de esa forma de entender la religión, en tanto que pone el acento en que una adecuada concepción del ser humano nunca debe olvidar la dimensión espiritual de este (Überwelt) por ser la dimensión más propiamente humana y existencial. Esta incluye nuestros valores, ideales o sistema de creencias y es la dimensión que nos remite a la búsqueda de sentido último y la que nos aboca a preguntas fundamentales para el terapeuta existencial relacionadas con la nada o el vacío, la muerte o el significado de la existencia. Se identifica con la cosmovisión de la persona y muchas veces entraña tensiones entre el sentido y el absurdo, la esperanza y la desesperación.

La interpretación adecuada de la obra de Rollo May y la que puede servir de guía al terapeuta actual es aquella que nos invita a no olvidar la dimensión espiritual del ser humano, esa que nos conecta con los valores y que nos recuerda, más allá del nihilismo, que no todo está permitido ni todo es dador de sentido, aunque a veces, justamente por ello, conduzca a dilemas irresolubles. Y estas ideas que impregnan las páginas de toda la obra de May fueron, en gran medida, aprendidas de su maestro Paul Tillich, de quien también aprendió: a emocionarse con la filosofía, a valorar la duda como símbolo de valentía y de crecimiento personal, y a comprender que el "eros entre profesor y alumno es la esencia de la buena enseñanza"12 (May, 1988, p. 122).

Esta última idea, la de la importancia del eros entre profesor y alumno, será una idea que May trasladará a su profesión como psicoterapeuta. Convencido de que la relación entre terapeuta y paciente debe ser una relación valiosa y profunda, entiende que esta relación es una relación que 
implica eros, no en el sentido pasional (erótico), sino en el sentido amoroso de aquel que cuida y se preocupa por el otro:

El cuidado es un tipo particular de intencionalidad que se manifiesta especialmente en psicoterapia. Significa desearle bien a alguien; y si el terapeuta no lo experimenta él mismo o si no cree que lo que le ocurre al paciente importa.... iAy de la terapia! La significación original y común de la "intencionalidad" y el "cuidado" está en la palabrita tender (en inglés tend), que es la raíz tanto de "intencionalidad" como de atender (en el sentido de prodigar cuidado). Tender designa una tendencia, una inclinación hacia, un movimiento por el cual descarga uno su peso en un determinado lado; y también significa atender, mostrar solicitud. En este sentido es tanto la fuente del amor como de la voluntad (May, 1985b, p. 234). 


\section{REFERENCIAS}

Diéguez, A. (2017). Transhumanismo: la búsqueda tecnológica del mejoramiento humano. Barcelona: Herder.

Domínguez, X.M. (2011). Psicología de la persona. Madrid: Palabra.

Frankl, V. (2003). Ante el vacío existencial. Barcelona: Herder.

Frankl, V. (2004). El hombre en busca de sentido. Barcelona: Herder.

Frankl, V. (2014). En el principio era el sentido. Barcelona: Paidós.

Hadot, P. (1998). ¿Qué es la filosofía antigua? Fondo de Cultura Económica: Madrid.

Heidegger, M. (1993). Ser y tiempo. Madrid. Fondo de Cultura Económica.

James, W. (1999). Las variedades de la experiencia religiosa. Barcelona: Península.
Martínez Robles, Y.A. (2012). Terapia existencial. México: Círculo de Estudios en Psicoterapia Existencial.

May, R. (1967). The art of counseling. Nashville: Abingdon.

May, R. (1985a). El hombre en busca de sí mismo. Buenos Aires: Central.

May, R. (1985b). Amor y voluntad. Barcelona: Gedisa.

May, R. (1988). Paulus. Tillich as Spiritual teacher. Dallas: Saybrook.

May, R. (2000). El dilema del hombre. Barcelona: Gedisa.

Pascal, B. (1983). Obras. Madrid: Alfaguara.

Reale, G. (2000). La sabiduría antigua. Barcelona: Herder.

Tillich, P. (1973). El coraje de existir. Barcelona: Laia.

Van Deurzen-Smith, E. (1993). Existential Counselling in Practice. London: SAGE Publications.

Yalom, I.D. (1984). Psicoterapia existencial. Barcelona: Herder. 


\section{NOTAS}

1 May define esta "presencia escénica" de Tillich por dos características principalmente: por vivir el significado de todo aquello que decía en sus conferencias, y por la capacidad de atención plena a aquel con el que estuviera (May, 1988).

2 La segunda parte (compuesta por los capítulos 4 y 5) de la obra El dilema del hombre de Rollo May corresponde, en su totalidad, a la aportación de May a la obra colectiva Angustia normal y patológica publicada en 1968. El capítulo 4 de El dilema del hombre se corresponde con la introducción de la obra colectiva citada, mientras que el capítulo 5 se corresponde con el apartado 5 de la primera parte, cuyo título reza "Teorías de la angustia".

3 Nos referimos aquí a la psicoterapia dominante en los ámbitos de la salud mental. Quedan excluidas, obviamente, las de corte fenomenológico-existencial, que asumen el dolor de la existencia como un factor intrínseco de la misma. En ese sentido quisiéramos destacar también la aportación de Viktor Frankl a esta aceptación de la angustia como factor humano: "Niego tajantemente que la búsqueda de un sentido para la propia existencia, o la duda de si realmente existe un sentido, proceda siempre de una enfermedad o sea el resultado de una enfermedad. La frustración existencial no es en sí misma ni patológica ni patogénica. La preocupación, o la desesperación, por encontrarle a la vida un sentido valioso es una angustia espiritual, pero en modo alguno representa una enfermedad" (Frankl, 2004. p. 126).

$4 \quad$ Junto con la libertad, estos tres temas (sentido de la vida, muerte y aislamiento) son señalados por Irvin Yalom (uno de los máximos exponentes de la terapia existencial americana y discípulo de May) como las preocupaciones básicas del ser humano. $5 \quad$ Viktor Frankl nos habla en su obra de un sentido último y general que no es aprehensible por la ciencia. Un metasentido que va más allá de nuestra capacidad de captación racional (Frankl, 2014, p. 53). Es ese sentido último el que se conserva bajo todas las condiciones de la existencia, incluso el sufrimiento (Frankl, 2003, p. 34). "Este sentido último excede y sobrepasa, lógicamente, la capacidad intelectual del hombre: a este contexto que sobrepasa la limitación humana lo denominamos en logoterapia suprasentido. Al hombre no se le reclama, como predican muchos filósofos existencialistas, que soporte lo absurdo de la vida, al contrario, se le pide que asuma racionalmente su propia capacidad para captar la sensatez incondicional de la vida. El logos es más profundo que la lógica" (Frankl, 2004, p. 140).

Por otra parte, cuando Frankl afirma que "la existencia humana tiende siempre más allá de sí misma, tiende siempre hacia un sentido" (Frankl, 2003, p. 111) está mostrando una posición afín a la mantenida por Rollo May cuando afirma que el sentido último nos arranca de nuestra egocentricidad.

Por último, sería interesante señalar la postura que, como terapeuta, mantiene Frankl respecto de la relación entre la religión y la psicoterapia. Al respecto se nos dice que, si se plantea en la terapia la pregunta por el sentido y se contempla "el fenómeno de la fe no como fe en Dios, sino como fe en un sentido más universal, entonces resulta del todo legítimo contemplar el fenómeno de la fe y ocuparse de él" (Frankl, 2003, p. 112). Dicha afirmación se completa con una referencia a Paul Tillich y su forma de entender la religión, a la que Frankl se une: "Me gustaría solo añadir que algo parecido había dicho ya Paul Tillich, cuando nos ofreció la siguiente definición: «Ser religioso significa plantearse apasionadamente la pregunta del sentido de nuestra existencia»" (Frankl, 2003, p. 114).

$6 \quad$ En su obra The art of couselling. Capítulo X.

7 Véase A. Diéguez (2017). Transhumanismo: la búsqueda tecnológica del mejoramiento humano. Herder.

8 Esto no siempre había sido así. Cuando la psicología formaba parte de la filosofía, es decir, antes de que adquiriese el carácter de ciencia positiva en el siglo XIX, no existía el rechazo a la dimensión espiritual del ser humano que luego encontraremos en muchas de las escuelas psicológicas dominantes.

Así, la mayoría de las escuelas filosóficas dominantes en la Antigüedad (desde Sócrates hasta las Escuelas Helenísticas) entendían que el cuidado del alma era uno de sus mayores objetivos. "La filosofía, tal como es concebida en la Antigüedad, es, antes que nada, un ejercicio espiritual, una auténtica terapéutica, una manera de ver y vivir el mundo y un esfuerzo de transformación del ser humano" (Torralba, 2016, p. 47). Esos ejercicios espirituales, tal como los ha entendido el filósofo Pierre Hadot (1998), eran prácticas de vida encaminadas a operar una modificación en aquel que las realiza con el objetivo de llevar una "buena vida". Según Hadot, encontramos estas prácticas espirituales en Sócrates, Platón, Aristóteles, el cinismo, el estoicismo, el escepticismo y el epicureísmo, y muchas de ellas tenían un carácter espiritual o religioso como la contemplación, la meditación o el cultivo del conocimiento. En su libro La sabiduría antigua, Giovanni Reale toma prestadas estas palabras de Séneca para ilustrar esta manera terapéutica de entender la filosofía: "[...] antes de nada quisiera decirte que estas cosas en las que encontré alivio han tenido para mí la eficacia de una medicina; las buenas exhortaciones se transforman en medicina y cualquier cosa que alivie el alma favorece también el cuerpo. El estudio ha sido mi salvación; es mérito de la filosofía si me levanto del lecho, si me cuido: a ella le debo la vida, aunque esta sea la menor deuda que tengo con ella" (Reale, 2000, p. 20).

Pero no solo en la filosofía antigua encontramos esta ausencia de rechazo a la dimensión espiritual del ser humano. Otros ejemplos de la historia de la filosofía (o historia de la psicología, porque, como hemos dicho, aún no se había llevado a cabo la separación entre ambas) podrían ser San Agustín (que en las Confesiones ofrece un maravilloso retrato del espíritu humano como sede de la intimidad mediante un ejercicio de introspección) o Descartes (quien situó el yo en el alma, entidad autónoma perteneciente a la sustancia pensante).

Pero cuando la psicología quiere convertirse en ciencia positiva debe, para lograrlo, asumir los axiomas de la ciencia: atender a lo empíricamente constatable y dejar fuera lo que no pueda ser comprobado mediante el método científico. A partir de ahora, la dimensión espiritual del ser humano será olvidada (cuando no negada) por la mayoría de los psicólogos (no incluimos aquí el amplio abanico que conforman los psicólogos Humanistas, a los que Irvin Yalom denomina "nuestros primos estadounidenses" en su obra Psicoterapia Existencial, en su intento por comprender al ser humano de forma integral, para quienes lo espiritual hace referencia a la dimensión que propiamente personaliza e individualiza al ser humano). 
9 Utilizamos aquí el concepto de sano no en oposición al concepto de enfermedad, sino al concepto de sinsentido. Estos valores objetivos son la base para no caer en la ansiedad neurótica o patológica.

10 En su conocida obra Las variaciones de la experiencia religiosa dice que la religión institucional se caracteriza porque sus elementos son el culto, el sacrificio, los rituales y la organización eclesiástica.

11 Como señala Rollo May, Tillich se ganó en más de una ocasión el adjetivo de ateo por afirmar que demostrar la existencia de Dios es negarlo, ya que Dios está más allá de la existencia (May, 1988).

12 Traducción propia. 